\title{
Changes of exhaled nitric oxide during steroid treatment of childhood asthma
}

\author{
J. Beck-Ripp, M. Griese, S. Arenz, C. Köring, B. Pasqualoni, P. Bufler
}

Changes of exhaled nitric oxide during steroid treatment of childhood asthma. J. BeckRipp, M. Griese, S. Arenz, C.Köring, B. Pasqualoni, P. Bufler. (C) ERS Journals Ltd 2002.

ABSTRACT: Exhaled nitric oxide (eNO) is elevated in several inflammatory airway diseases and is significantly reduced by anti-inflammatory treatment with inhaled steroids. The aim of this randomized, open clinical trial was to evaluate eNO in relation to conventional lung function parameters at rest and after exercise during sequential changes of inhaled steroids in children with persistent asthma.

The study consisted of a 4 week run-in period, a 4 week washout phase and a randomized treatment period during which only one group was treated again with inhaled budesonide.

After run-in, eNO was reduced to normal values, and rose again during washout. In the patients randomized to steroid treatment, eNO was again decreased, whereas it remained unchanged in the untreated patients. Forced expiratory volume in one second and forced vital capacity at rest and after exercise improved significantly after run-in, but showed no difference after randomization. However there was a strong correlation of eNO with patient compliance.

Exhaled nitric oxide was able to differentiate between children briefly treated with or without steroids, the conventional lung-function variables however could not. In practice exhaled nitric oxide may thus be a valuable parameter to monitor adherence to steroids, but less suitable to describe physiologically relevant impairments of lung function.

Eur Respir J 2002; 19: 1015-1019.
Dr von Hauner Children's Hospital, Ludwig-Maximilians-University, Munich, Germany.

Correspondence: M. Griese, Kinderklinik and Kinderpoliklinik im Dr. von Haunerschen Kinderspital, LudwigMaximilians-University, Pettenkoferstrasse 8a, D-80336 Munich, Germany. Fax: 498951603477

E-mail: griese@pk-i.med. uni-muenchen.de

Keywords: Asthma inhaled steroids nitric oxide

Received: September 82001 Accepted after revision January 12 2002

This study was supported by Astra GmbH (Wedel, Germany).
Allergic asthma is characterized by a chronic inflammation of the airways with enhanced mucus secretion, and contraction and hypertrophy of the bronchial muscles driven by repeated allergen exposure. For optimal guidance of anti-asthmatic drug therapy continuous information on the degree of airway inflammation is desirable. Symptom scores, repeated spirometry or home peak-flow measurements are only indirect measures of the degree of airway inflammation [1] and direct measures like bronchoalveolar lavage or bronchial biopsy are too invasive to be performed in the management of asthmatic children. Great expectations have been held for direct variables of inflammation like nitric oxide (NO) concentrations that can be easily assessed in exhaled air. NO is produced by various lung cells from the amino acid L-arginine by different iso-enzymes of NO synthase (NOS) and elevated concentrations have been measured in the exhaled air of asthmatic adults [2] and children [3-5]. The expression of one of the iso-enzymes, the inducible NO synthase (NOS2, iNOS) is upregulated by inflammatory cytokines [6-8] leading to an increase of exhaled NO (eNO) in inflammatory airway disease, whereas an inhibition of the iNOS via corticosteroids reduces eNO in asthmatics but not in healthy subjects $[2,8-10]$.

Short-term application of steroids can normalize eNO [3, 10-12] to baseline values and leads to significant improvement of lung-function variables in asthmatic children [13]. So far however, it is not known if eNO corresponds to asthma symptoms or lung-function variables on a medium- or long-term basis, and there appears to be only a very loose prediction of lung- function changes by changes in eNO [14]. It is of great interest to identify conditions in which eNO might be of use in adjusting the dose of inhaled steroids for asthma treatment in children.

The aim of this study was to evaluate eNO in relation to conventional lung-function parameters, at rest and after exercise, during sequential changes of inhaled steroids in children with asthma and to thus determine its possible value as a noninvasive marker of inflammation during intervention.

\section{Methods}

\section{Patients}

Fifty-four patients aged 6-16 yrs with mild-tomoderate persistent asthma were recruited from the Paediatric Pulmonology and Allergology outpatient clinic of the Munich University Childrens' Hospital between February 1998-November 1999. Their asthma was diagnosed before treatment, according to the recommendations of the National Heart, Lung 
and Blood Institute (NHLBI) Expert Panel Report [15]. Patients who had received oral or inhaled steroid treatment during the last 2 months, had acute upper airway infection, had a history of bad compliance $(<65 \%$ of prescribed medication) or had any other serious illness were excluded. Children with a poor Turbohaler $\AA$ (Pulmicort Turbohaler $\AA$, Astra $\mathrm{GmbH}$, Wedel, Germany) inhalation technique, acute asthma attacks, unstable asthma or other severe intercurrent disease were withdrawn from participation. The study was approved by the local ethics committee and informed consent was obtained from all patients and their parents.

\section{Study design}

The study was conducted as a randomized, open clinical trial. It consisted of a 4 week run-in period, a 4 week washout phase and a randomized treatment period of 8 weeks. During run-in, patients received two doses of inhaled budesonide, twice daily, via a $200 \mu \mathrm{g}$ Turbohaler $\AA$ inhalation device. Additional inhaled $\beta_{2}$-agonists (salbutamol $200 \mu \mathrm{g}$ or terbutaline $500 \mu \mathrm{g})$ were allowed during the whole study on demand (maximum of five times two puffs per day). At the end of the run-in period the inhaled steroids were discontinued for the 4 week washout period and only inhaled $\beta_{2}$-agonists were used as needed. At the third visit the patients were randomized to one of the following two therapeutic regimen for another 8 weeks. One group received low-dose inhaled budesonide twice daily, one $200 \mu \mathrm{g}$ dose via Pulmicort Turbohaler $\AA$ with additional inhaled $\beta_{2}$-agonists on demand, the other group received no further steroids, only inhaled $\beta_{2}$-agonists as needed. During run-in 54 patients ( 35 male, $10.0 \pm 0.4$ yrs, range $6.2-16.3 \mathrm{yrs}$ ) were recruited. A total of 20 children dropped out, due to various conditions, leaving 34 who agreed to randomization.

\section{Assessments}

NO concentrations (parts per billion (ppb)) in exhaled air were measured as recommended by the European Respiratory Society [16]. They were carried out on-line, before spirometry, by chemiluminescence analysis in the LR 2000 NO analyser (Logan Research, Rochester, Kent, UK), which is sensitive to eNO at concentrations of $1-5000 \mathrm{ppb}$, by volume, as described previously [14].

Spirometry was performed in a Jäger MasterLab (Jäger, Würzburg, Germany) and the forced expiratory volume in one second (FEV1), forced vital capacity (FVC) and mean maximal expiratory flow (MMEF) were measured according to the recommendations of the American Thoracic Society (ATS) [17]. The reference values of ZAPLETAL were used [18]. Shortacting $\beta_{2}$-agonists were not taken up to $8 \mathrm{~h}$ before lung-function testing. Lung function was assessed at rest and $10 \mathrm{~min}$ after $6 \mathrm{~min}$ of standardized fastfree running (cardiac frequency $\geqslant 170$ beats $\cdot \mathrm{min}^{-1}$ ) to test for bronchial hyperreactivity. Results are given as per cent of predicted (lung function at rest); lung function after exertion was calculated as remaining per cent of lung function at rest.

\section{Compliance}

To monitor compliance patients received a new Pulmicort Turbohaler $\AA$ for each steroid treatment course which had to be returned for evaluation at the next visit. The amount of medication actually taken was assessed by counting the number of remaining doses of budesonide by turning the wheel on the Turbohaler $\AA$ until the red mark on the dose indicator had reached an upright position. The unused doses were subtracted from a total of 200 doses in the Turbohaler $\AA$ to estimate the administered number of doses. Compliance was calculated as doses taken/ doses prescribed $\times 100(\%)$.

\section{Statistical analysis}

All variables analysed were normally distributed. Deviations from Gaussian distribution were checked by using the Kolmogorov-Smirnov test with a p-value from DALLAL and WILKINSON's approximation to Lilliefors's method [19] calculated by Graph Pad Prism (San Diego, CA, USA). Results are presented as mean \pm SEM in $n$ subjects, unless otherwise stated. Changes in lung- function variables or NO concentrations over the study period were assessed by repeated measures analysis of variance, followed by a Newman-Keuls post-test if $\mathrm{p}<0.05$. Differences between the two randomized groups were analysed by unpaired t-tests. Linear regression was used for correlation analysis of the variables. The power of the study to detect a difference in FEV 1 of $5 \%$ at a $\mathrm{p}<0.05$ was $80 \%$.

\section{Results}

\section{Randomization and symptom scores}

Of the 34 children randomized, three did not return for final evaluation, resulting in 31 patients $(16$ male, $10.5 \pm 0.5$ yrs, range $6.2-14.8$ yrs) who completed the study. A total number of 15 patients (eight male, $9.8 \pm 0.7 \mathrm{yrs}$, range $6.2-14.7 \mathrm{yrs}$ ) were randomized to treatment with inhaled steroids plus inhaled $\beta_{2}$-agonists as needed and 16 of them (eight male, $11.07 \pm 0.6$ yrs, range $6.8-14.8$ yrs) to treatment with inhaled $\beta_{2}$-agonists as needed. There were no differences between the two groups regarding age, sex, compliance, eNO and lung function at any time, except for a lower MMEF at rest and after exertion before randomization in those treated again with inhaled steroids.

\section{Nitric oxide}

During the run-in period, mean NO (fig. 1a) was significantly reduced from $14.8 \pm 1.9 \mathrm{ppb}$ to values in 

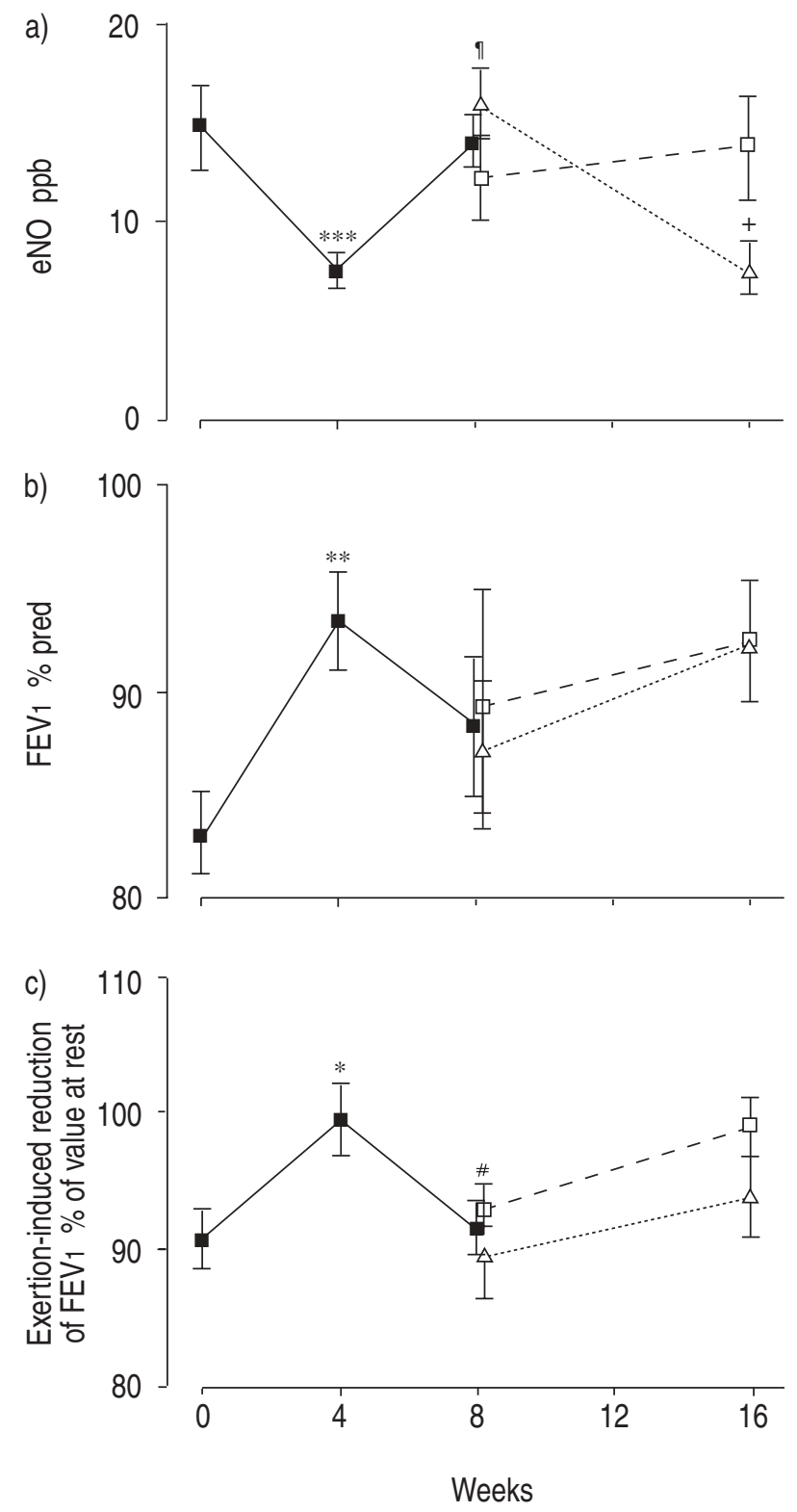

Fig. 1.-a) Exhaled nitric oxide (eNO), b) forced expiratory volume $\left(F^{2} V_{1}\right)$ at rest and $\left.c\right)$ exertion-induced reduction of FEV 1 during the study. Values are presented as means \pm SEM of all patients $(\boldsymbol{\square}: \mathrm{n}=31)$, patients randomized to budesonide treatment $(\triangle: n=15)$ and patients without budesonide treatment $(\square: n=16)$. For statistical analysis repeated measures analysis of variance was calculated over the different time points. If $\mathrm{p}<0.05$, a NewmanKeuls post-test was used for comparisons within a treatment group (*: $\mathrm{p}<0.05 ; * *: \mathrm{p}<0.01 ; * * *: \mathrm{p}<0.001$ (before treatment to after run-in)); ${ }^{\#}: \mathrm{p}<0.05 ;{ }^{\uparrow}: 0.001$ (after run-in to after wash-out); $+: \mathrm{p}<0.01$ (before randomization to after randomization). For analysis of differences between both treatment groups at the end of the study, the unpaired t-test was used ( $<<0.05$ in a).

the normal range, after 4 weeks of $2 \times 400 \mu \mathrm{g}$ inhaled budesonide $(7.6 \pm 0.8 \mathrm{ppb}, \mathrm{p}<0.001)$. After steroids had been discontinued for 4 weeks, eNO significantly increased again $(14.0 \pm 1.2 \mathrm{ppb}, \mathrm{p}<0.001)$ back to initial values. After randomization, eNO of the untreated group remained unchanged $(13.8 \pm 2.5 \mathrm{ppb}$, $\mathrm{p}>0.05)$ while eNO after low-dose inhaled steroids $(2 \times 200 \mu$ g budesonide) was again significantly reduced
$(7.7 \pm 1.2 \mathrm{ppb}, \mathrm{p}<0.01)$ and therefore was able to differentiate between children briefly treated with or without steroids $(\mathrm{p}<0.05)$.

\section{Lung function}

Lung function at rest is depicted in table 1 and figure $1 \mathrm{~b}$. The initial 4-week inhaled budesonide treatment course (Pulmicort Turbohaler $\mathbb{R}, 2 \times 400 \mu \mathrm{g}$ ) resulted in an increase in the FEV $1 \quad(p<0.01)$, MMEF $(\mathrm{p}<0.01)$ and FVC $(\mathrm{p}>0.05)$. After washout FEV1, FVC and MMEF of all the patients were reduced, but only changes in the later were significant. At the end of the 8-week randomized treatment period, no significant changes and no differences between either groups were observed.

Lung-function values after exertion are given in figure 1c. Exertion-induced reduction of FEV1 improved after high-dose inhaled steroids $(\mathrm{p}<0.05)$ and deteriorated again after washout $(\mathrm{p}<0.05)$. Again, both groups did not differ significantly before and after the 8-week randomization period. Similar results were obtained for FVC and MMEF (data not shown).

Neither lung-function parameters at rest nor after exertion were able to establish a difference between children briefly treated with or without steroids.

\section{Compliance}

A positive correlation was established between the patients' compliance to take their prescribed inhaled steroid medication and the reduction of eNO (fig. 2). With a better compliance with budesonide Turbohaler $\mathbb{R}$ a greater reduction of eNO during the run-in period was observed $\left(\mathrm{p}=0.0003, \mathrm{r}^{2}=0.5863\right)$.

\section{Discussion}

The aim of this trial was to evaluate eNO in relation to conventional lung-function parameters, at rest and after exercise, during sequential changes of inhaled steroids in children with persistent asthma. It became obvious that only eNO values, but not the conventional lung-function variables, were able to mark a clear difference between children briefly treated with or without steroids. This indicated that guidance of inhaled steroid therapy by eNO may be complicated by different response times or complex inter-relations of the variables used to assess the activity of the asthmatic disease.

Various studies have, so far, investigated lung function and eNO in asthmatic children [20-26]. In a prospective, open, nonrandomized study the authors recently showed a lack of correlation between eNO and disease severity and only a weak prediction of the physician-recommended inhaled therapy by eNO in children with allergic asthma [14]. In contrast to the majority of cross-sectionally designed investigations, this study investigated 31 asthmatic children who were longitudinally followed before and during treatment with different doses of inhaled steroids. 
Table 1. - Lung-function parameters at rest and exhaled nitric oxide (eNO) measurement

\begin{tabular}{|c|c|c|c|c|c|c|}
\hline \multirow[t]{2}{*}{ Variable } & \multirow[t]{2}{*}{ Patients $n$} & \multicolumn{4}{|c|}{ Week } & \multirow[t]{2}{*}{ p-value } \\
\hline & & 0 & 4 & 8 & 16 & \\
\hline \multicolumn{7}{|l|}{ FEV $1 \%$ pred } \\
\hline All & 31 & $83.1 \pm 2.0$ & $93.4 \pm 2.4 * *$ & $88.2 \pm 3.3$ & & 0.0124 \\
\hline Steroids & 15 & & & & $92.3 \pm 2.7^{+}$ & \\
\hline \multirow{2}{*}{\multicolumn{7}{|c|}{ MMEF \% pred }} \\
\hline & & & & & & \\
\hline All & 31 & $65.3 \pm 2.9$ & $81.6 \pm 4.6^{* *}$ & $77.4 \pm 4.5^{\bullet}$ & & 0.0041 \\
\hline Steroids & 15 & & & & $81.3 \pm 5.0^{+}$ & \\
\hline No steroids & 16 & & & & $83.3 \pm 7.1$ & \\
\hline \multicolumn{7}{|l|}{ FVC $\%$ pred } \\
\hline All & 31 & $85.7 \pm 2.0$ & $90.5 \pm 2.5$ & $88.7 \pm 1.8$ & & 0.1132 \\
\hline Steroids & 15 & & & & $89.8 \pm 2.8^{+}$ & \\
\hline No steroids & 16 & & & & $87.8 \pm 2.2$ & \\
\hline \multicolumn{7}{|l|}{ eNO ppb } \\
\hline All & 31 & $14.8 \pm 1.9$ & $7.6 \pm 0.8^{* * *}$ & $14.0 \pm 1.2^{f}$ & & 0.0001 \\
\hline Steroids & 15 & & & & $7.7 \pm 1.2^{\S}$ & \\
\hline No steroids & 16 & & & & $13.8 \pm 2.5$ & \\
\hline
\end{tabular}

Values are presented as mean \pm SEM of $\mathrm{n}$ patients. FEV1: forced expiratory volume in one second; MMEF: mean maximal expiratory flow; FVC: forced vital capacity. "\#: first repeated measures analysis of variance was calculated over the different time points. If $\mathrm{p}<0.05$, a Newman-Keuls post-tests was used for comparisons within a treatment group; **: $\mathrm{p}<0.01 ; * * *$ : $\mathrm{p}<0.001$ (before treatment to after run-in); ${ }^{\uparrow}: \mathrm{p}<0.05$ (before treatment to after wash-out); ${ }^{f}: \mathrm{p}<0.001$ (after run-in to after washout). If $\mathrm{p}>0.05$, no further calculations were made. For analysis of differences between both treatment groups (steroids and no sterioids), the unpaired t-test was used: ${ }^{+}: \mathrm{NS} ;$ s: $\mathrm{p}<0.05$.

Within the given time frame, only readily responding eNO, possibly from inhibition of the NOS2 by the corticosteroids [8,9], but not conventional lungfunction variables, were able to identify patients randomized to treatment with steroids.

This divergence of eNO and the functional measurements clearly show that these variables assess different aspects of asthmatic inflammatory disease. Spacial differences within the lungs are not likely to be responsible for the divergence between eNO and lung function. It has been proposed that FEV1 may reflect the more central airways and that eNO may sample the more distal air spaces [22]. However, the authors did not find a concordance with MMEF (table 1) or

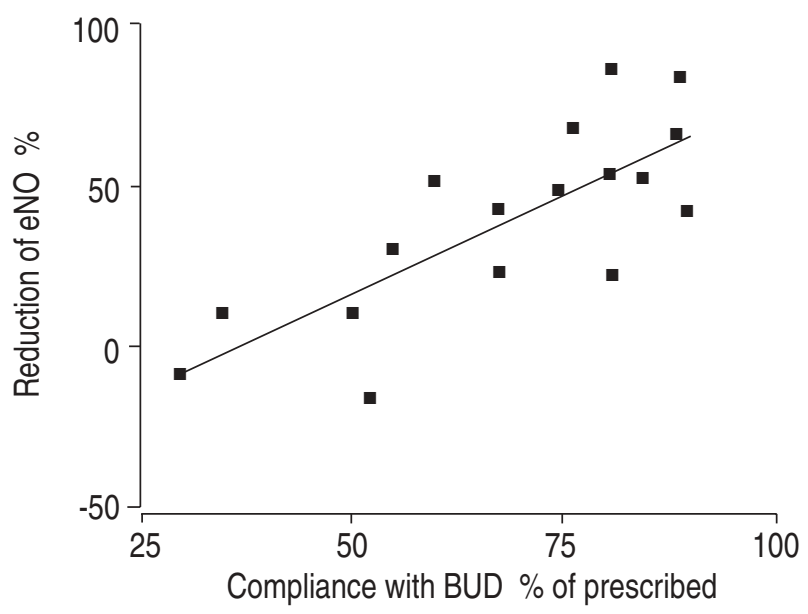

Fig. 2. - Positive correlation between the reduction of exhaled nitric oxide (eNO) and the compliance with inhaled budesonide (BUD) during the 4 -week run-in period $\left(n=17, p=0.0003, r^{2}=0.5863\right)$. For statistical analysis linear regression was used. the maximum expiratory flow at $25 \%$ vital capacity (data not shown).

The observed differences in the response to inhaled steroids are most likely explained by different sensitivities of the various components of the asthmatic inflammatory reaction. Whereas eNO is readily affected, neither exercise-induced changes in FEV1 nor FEV1 at rest were significantly altered compared to the group of children not randomized to steroid treatment. These observations are supported by the study of JATAKANON et al. [27] investigating adults with mild asthma during short-term treatment with different doses of inhaled budesonide. Whereas eNO reached minimum values with a dose of $400 \mu \mathrm{g}$ budesonide, sputum eosinophils and the provocative concentration of methacholine causing a $20 \%$ fall in FEV1 were further reduced after quadrupling the dose of the inhaled steroids. Similarly, it has been shown that in adult asthmatics, the administration of the selective NOS2 inhibitor $N(\mathrm{G})$-monomethyl-Larginine by nebulization, significantly reduced eNO but had no effect on FEV1 [9].

The present data, indicating the inverse correlation between levels of eNO and adherence to steroid inhalation therapy, opens up new possibilities for monitoring patient compliance, which may be poor in some asthmatic patients. In patients on steroids, low levels suggest that medication has been inhaled, but it does not indicate if sufficient medication to control the asthmatic disease has been prescribed and actually taken. Whether guidance of inhaled steroid treatment by eNO leads to under- or overtreatment of asthmatic children cannot be answered with the data available and must be clarified in a study directly addressing this issue. To verify this aspect of the usefulness of eNO for monitoring adherence, a study 
using an electronic recording device to prevent any manipulation is necessary. Unfortunately such a device was not available for use with the Turbohaler $\mathbb{R}$ inhalation device when the investigation was initiated.

Exhaled nitric oxide is able to differentiate between asthmatic children briefly treated with or without steroids, however, the conventional lung-function variables cannot. It is concluded that currently, exhaled nitric oxide cannot easily be used for guiding steroid inhalation therapy as it does not mirror physiologically relevant changes of lung function. Conversely, the ready response of exhaled nitric oxide makes it a useful tool to monitor adherence to steroids, which is often poor in asthmatics and thus it may significantly contribute to the management of anti-inflammatory treatment in these patients.

Acknowledgements. The authors would like to thank I. Gratz, C. Manstetten and M. Panhans for their technical assistance.

\section{References}

1. Sont JK, Han J, van Krieken JM, et al. Relationship between inflammatory infiltrate in bronchial biopsy specimen and clinical severity of asthma patients treated with inhaled steroids. Thorax 1996; 51: 496502.

2. Kharitonov S, Yates D, Robbins R, Logan-Sinclair R, Shinebourne E, Barnes P. Increased nitric oxide in exhaled air of asthmatic patients. Lancet 1994; 343 : 133-135.

3. Byrnes C, Dinarevic S, Shinebourne E, Barnes P, Bush A. Exhaled nitric oxide measurements in normal and asthmatic children. Pediatr Pulmonol 1997; 24: 312 318.

4. Beck J, Griese M, Latzin P, Reinhardt D. Characteristics of flow dependency of nitric oxide in exhaled air in children with cystic fibrosis and asthma. Eur J Med Res 1999; 4: 335-340.

5. Dötsch J, Demirakca S, Terbrack H, Hüls G, Rascher W, Kühl P. Airway nitric oxide in asthmatic children and patients with cystic fibrosis. Eur Respir J 1996; 9: $2537-2540$

6. Nathan C, Xie Q. Nitric oxide synthases roles, tolls and controls. Cell 1994; 78: 915-918.

7. Barnes P. Nitric oxide and airway disease. Ann Med 1995; 27: 389-393.

8. Hamid Q, Springall DR, Riveros-Moreno V, et al. Induction of nitric oxide synthetase in asthma. Lancet 1993; 342: 1510-1513.

9. Yates $\mathrm{D}$, Kharitonov $\mathrm{S}$, Robbins $\mathrm{R}$, Thomas $\mathrm{P}$, Barnes P. Effect of a nitric oxide synthase inhibitor and a glucocorticosteroid on exhaled nitric oxide. $\mathrm{Am}$ J Respir Crit Care Med 1995; 152: 892-896.

10. Baraldi E, Azzolin N, Zanconato S, Dario C, Zacchello F. Corticosteroids decrease exhaled nitric oxide in children with acute asthma. J Pediatr 1997; 131: 381-385.

11. Kharitonov SA, Yates DH, Barnes PJ. Inhaled glucocorticoids decrease nitric oxide in exhaled air of asthmatic patients. Am J Respir Crit Care Med 1996; 153: 454-457.

12. Lanz MJ, Leung DYM, White CW. Comparison of exhaled nitric oxide to spirometry during emergency treatment of asthma exacerbations with glucocorticoids in children. Ann Allergy Asthma Immunol 1999; 82: $161-164$

13. Pedersen S, Hansen OR. Budesonide treatment of moderate and severe asthma in children: a doseresponse study. J Allergy Clin Immunol 1995; 95: 29_ 33.

14. Griese M, Koch M, Latzin P, Beck J. Asthma severity, recommended changes of inhaled steroid therapy and exhaled nitric oxide in children: a prospective blinded trial. Eur J Med Res 2000; 5: 334-340.

15. Sheffer AL, Taggart VS. The National Asthma Education Program. Expert panel report guidelines for the diagnosis and management of asthma. National Heart, Lung and Blood Institute. Med Care 1993; 31: Suppl. 3, MS20-MS28.

16. Kharitonov SA, Alving K, Barnes PJ. Exhaled and nasal nitric oxide measurements: recommendations. Eur Respir J 1997; 10: 1683-1693.

17. American Thoracic Society. Standardization of spirometry - 1994 update. Am J Respir Crit Care Med 1995; 152: $1107-1136$

18. Zapletal A. Lung function in children and adolescents. In: Herzog $\mathrm{H}$, ed. Progress in Respiration Research. Basel, Karger, 1987; pp. 173-196.

19. Dallal GE, Wilkinson L. An analytic approximation to the distribution of Lilliefors's test statistic for normality. Am Statistician 1986; 40: 294-296.

20. Dupont LJ, Rochette F, Demedts MG, Verleden GM. Exhaled nitric oxide correlates with airway hyperresponsiveness in steroid-native patients with asthma. Am J Respir Crit Care Med 1998; 157: 894-898.

21. Lim S, Jatakanon A, John M, et al. Effect of inhaled budesonide on lung function and airway inflammation: assessment by various inflammatory markers in mild asthma. Am J Respir Crit Care Med 1999; 159: 22-30.

22. Piacentini GL, Bodini A, Costella S, et al. Exhaled nitric oxide, serum ECP and airway responsiveness in mild asthmatic children. Eur Respir J 2000; 13: 839843

23. Scollo M, Zanconato S, Ongaro R, Zaramella C, Zacchello F, Baraldi E. Exhaled nitric oxide and exercise-induced bronchoconstriction in asthmatic children. Am J Respir Crit Care Med 2000; 161: 1047-1050.

24. Van Rensen ELJ, Straathof KCM, Veselic CMA, Zwinderman-Aeilko H, Bel EH, Sterk PJ. Effect of inhaled steroids on airway hyperresponsiveness, sputum eosinophils, and exhaled nitric oxide levels in patients with asthma. Thorax 1999; 54: 403-408.

25. Silvestri M, Spallarossa D, Frangova Yourukova V, Battistini E, Fregonese B, Rossi GA. Orally exhaled nitric oxide levels are related to the degree of blood eosinophilia in atopic children with mild-intermittent asthma. Eur Respir J 1999; 13: 321-326.

26. Piacentini GL, Bodini A, Costella S, et al. Exhaled nitric oxide and sputum eosinophil markers of inflammation in asthmatic children. Eur Respir $J$ 1999; 13: 1386-1390.

27. Jatakanon A, Kharitonov SA, Lim S, Barnes PJ. Effect of differing doses of inhaled budesonide on markers of airway inflammation in patients with mild asthma. Thorax 1999; 54: 108-114. 